\title{
Combustion Analysis of Diethyl Ether Blends in Gasoline Engine Operated with Ethanol
}

\author{
D. Balaji ${ }^{1, *}$, T. Maridurai ${ }^{2}$ and S. N. Mani Varmaa ${ }^{1}$ \\ ${ }^{1}$ Department of Automobile Engineering, Velammal Engineering College, Chennai-66, Tamilnadu, India \\ ${ }^{2}$ Department of Production Engineering, Velammal Engineering College, Chennai-66, Tamilnadu, India \\ *Corresponding author
}

\begin{abstract}
This paper investigates the effect of using unleaded gasoline with di ethyl ether blends on spark ignition engine (SI engine) performance, exhaust and combustion analysis. A four stroke, single cylinder SI engine was used for conducting this study. Exhaust emissions were analysed for carbon monoxide (CO), Hydrocarbon (HC), and Oxides of nitrogen (NOx) and carbon dioxide $\left(\mathrm{CO}_{2}\right)$ using unleaded gasoline, ethanol and di ethyl ether blends with different percentages of fuel at varying engine torque condition and constant engine speed. The result showed that the blending of unleaded gasoline with di ethyl ether increases the octane number and power output this may leads to increase the brake thermal efficiency. The CO, HC and NOx emissions concentrations in the engine exhaust decreases while the $\mathrm{CO}_{2}$ concentration increases. Using di ethyl ether as a fuel additive to unleaded gasoline causes an improvement in performance and significant reduction in exhaust emission.
\end{abstract}

Keywords-fuel additive; gasoline-di ethyl ether blend; exhaust emissions

\section{INTRODUCTION}

It is the dream of engineers and scientists to develop engines and fuels such that very few quantity of harmful emissions are generated, and these could be let into the surroundings without a major impact on the environment. Air pollution is predominately emitted through the exhaust of motor vehicles and the combustion of fossil fuels. Government around the world has set forth many regulatory laws to control the emissions. One of the serious problems facing the modern technological society is the drastic increase in environmental pollution by internal combustion engines (IC engines). All transport vehicles with SI and CI (compression ignition) engines are equally responsible for the emitting different kinds of pollutants. Some of these are primary kinds having direct hazardous effect such as carbon monoxide, hydrocarbons, nitrogen oxides etc, while others are secondary pollutants such as ozone, etc., which undergo a series of reactions in the atmosphere and become hazardous to health [3]. The emissions exhausted into the surroundings pollute the atmosphere and cause global warming, acid rain, smog, odours, and respiratory and other health hazards. The urgent need for alternative fuel is essential to replace the supplement conventional fuels. A pollutant is a component which changes the balance of environment and nature under normal condition. Carbon dioxide is not considered as pollutant as nature recycles it and produces oxygen but in a confined area if $\mathrm{CO}_{2}$ exceeds 5000 ppm then it becomes a potential health hazard [7],[9]. The root cause for these emissions is non-stoichiometric combustion, dissociation of nitrogen and impurities in the fuel and air. The transportation which uses IC engines is the major sector for the economic growth. The major exhaust emissions HC, CO, NOx, $\mathrm{SO}_{2}$, solid particles etc. are and performance is increased by adding the suitable additives to the fuel reduced with the present technology. Additives are integral part of today's fuel. Together with carefully formulated base fuel composition they contribute to efficiency and long life. They are chemicals, which are added in small quantities either to enhance fuel performance, or to correct a deficiency as desired by the current legislation. They can have surprisingly large effects even when added in little amount [10]. Additives are blended into fuel by refineries or end users. However use of metallic additives was subsequently discontinued mainly because of concern about the toxicity of the barium compounds in the exhaust emission. But the interest is revised recently to verify the possible use of additives to reduce emission level. Alcohol has been used as a fuel for Auto-engines since $19^{\text {th }}$ century; it is not widely used because of its high price. Alcohol is one of the fuel additive (Methanol, Ethanol) has some advantage over gasoline such as better antiknock characteristics and the reduction of $\mathrm{CO}$ and HC emissions. Houghton-Alico D [1] has made a study on alcohol production and potential. Several additives (oxygenated organic compounds) such as methanol, ethanol, tertiary butyl alcohol and methyl tertiary butyl ether are used as fuel additives. Although having these advantages, due to limitations in technology, economic and regional considerations alcohol fuel still cannot be used extensively. Since ethanol can be fermented and distilled from biomasses, it can be considered as renewable energy under the environmental consideration, using ethanol blended with gasoline is better than methanol because of its renewability and less toxicity. Many researchers have worked on the emission control and performance enhancement of SI engines. Winnington and Siddique [4] Hamdan, Jurban [5] and El-Kassaby [6] have studied the effect of using ethanolgasoline blends. They used maximum of $15 \%$ of ethanol in ATd 34 engine. Palmer F $\mathrm{H}$ [2] has conducted a test on gasoline engine containing oxygenates. The effect of oxygenate in gasoline on exhaust emission and performance in a single cylinder, four stroke SI engine was studied by Taljaard et al [8]. Ethanol can be produced form Azeotropic Solution by Pressure Swing Adsorption was studied by Pruksathorn and Vitidsant [11]. The effect of compressed natural Gas on performance and Emission in a Internal Combustion engine was studied by Semin et al [12], [13], [14]. 
Based on the economic and environmental considerations, an attempt has been made in this work to study the effects of di ethyl ether contents in the di ethyl ether-gasoline blended fuel on the engine performance and pollutant emission of a commercial SI engine. In the present work, to reduce the emissions and to improve the performance of petrol engine, the modification technique is used. Two fuel additives were mixed for this purpose. Various proportions of these fuel additives were mixed with the gasoline. The engine performance analysis and emission levels were measured, running the engine at varying load and constant speed. Encouraging results were obtained and the work carried out is presented. The objective of the present work is to investigate the effect of varying engine torque on the engine performance and exhaust emission working with different di ethyl ether fuel blends.

\section{EXPERIMENTAL SET UP AND METHOD}

The engine is a 100 cc 4 stroke, single cylinder SI engine loaded by an eddy current dynamometer. Table 1 lists some of the important specification of the engine under test. The schematic layout of the experimental set up is shown in fig 1 . The engine was coupled to a eddy current dynamometer which is equipped with an instrument cabinet fitted with a torque gauge, electric tachometer and switches for the load remote control. Fuel consumption was measured by using a calibrated burette and a stopwatch with an accuracy of 0.2s. The concentration of exhaust emission (CO, HC, NOx) and air fuel ratio were measured using a "Sun glass Analyser" MGA 1200. The analyser has a non-dispersive infrared molecule for CO, HC and NOx.

TABLE I. TABLE 1 ENGINE SPECIFICATIONS

\begin{tabular}{|c|c|}
\hline Engine make and model & Bajaj engine \\
\hline Engine type & Four stroke, Single cylinder air cooled engine \\
\hline Bore & $70 \mathrm{~mm}$ \\
\hline Stroke & $90 \mathrm{~mm}$ \\
\hline Cubic capacity & $100 \mathrm{cc}$ \\
\hline Compression ratio & $7.4: 1$ \\
\hline Rated power & $5.2 \mathrm{~kW}$ \\
\hline Rated speed & $6500 \mathrm{rpm}$ \\
\hline Fuel & Petrol \\
\hline
\end{tabular}

The engine was started and allowed to warm up for a period of 20-30 min. The air fuel ratio was adjusted to yield maximum power on unleaded gasoline. Engine test were performed at constant engine speed at $3 / 4^{\text {th }}$ throttle opening position by varying engine torque. The speed can be maintained constant by speed sensor. Before running the engine to a new fuel blend, it was allowed to run for sufficient time to consume the remaining fuel from the previous experiment. For each experiment, three runs were performed to obtain an average value of the experimental data. The variables that were continuously measured include engine speed (constant), torque, time required to consume 100 cc of fuel blend, CO, HC, NOx emission and exhaust gas temperature. The parameters such as fuel consumption rate, volumetric efficiency, brake power, brake thermal efficiency were estimated by standard equations. Table 1 shows the engine specification.

\section{RESULTS AND DISCUSSION}

The effect of di ethyl ether addition to unleaded gasoline on SI engine performance and exhaust emissions at $3 / 4^{\text {th }}$ throttle opening at various engine torque were investigated

\section{ETHYL ETHER- GASOLINE BLENDS}

\section{A. Performance Analysis}

1) Fuel consumption: The effect of ethanol and diethyl ether -unleaded petrol blends on the fuel consumption is shown in Figure I. This figure shows that the fuel consumption increases as the engine torque increases at constant engine speed. But as the percentage of diethyl ether increases the fuel consumption increases for the same torque. This behaviour is attributed to the LHV per unit mass of the ethanol and diethyl ether fuel, which is distinctly lower than that of the petrol fuel. Therefore the amount of fuel introduced in to the engine cylinder for a given desired fuel energy input has to be greater with the ethanol and diethyl ether fuel.

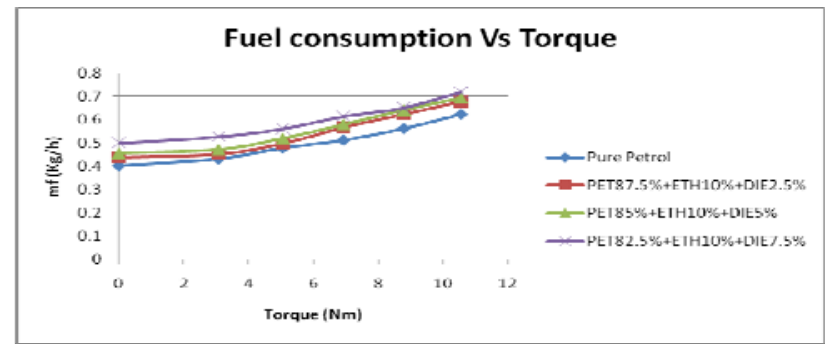

FIGURE I. VARIATION OF FUEL CONSUMPTION WITH ENGINE TORQUE

2) Specific energy consumption: The effect of using ethanol, diethyl ether, petrol blends on brake specific energy consumption (SEC) is shown in Figure II. Since ethanol and diethyl ether has low heating value than the pure petrol, in order to produce the same power at the same operating conditions, more fuel will be burned as the proportion of diethyl ether increases. As a result SEC increases.

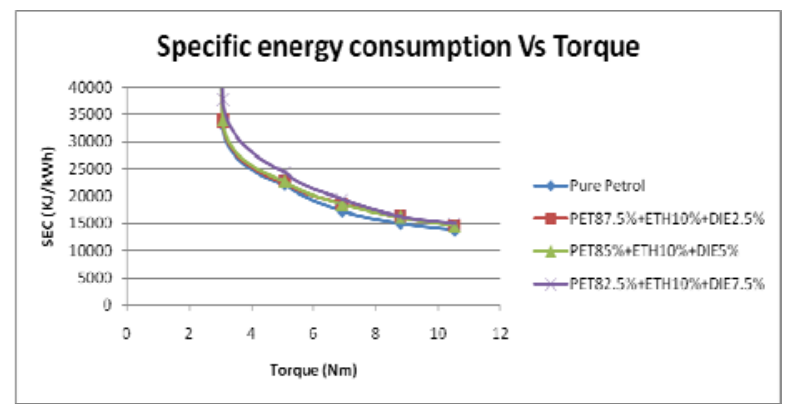

FIGURE II. VARIATION OF SPECIFIC ENERGY CONSUMPTION WITH ENGINE TORQUE 
3) Brake thermal efficiency: Figure III presents the effect of ethanol, diethyl ether - petrol blends on brake thermal efficiency. As shown in the figure brake thermal efficiency increases as the engine torque increases. The brake thermal efficiency at part load (50\% load) recorded with $10 \%$ ethanol and $2.5 \%$ diethyl ether in the fuel blend is about $15 \%$ and for $10 \%$ ethanol and $5 \%$ diethyl ether in the fuel blend is about $14.5 \%$ and for $10 \%$ ethanol and $7.5 \%$ diethyl ether in the fuel blend is about $14.8 \%$ at constant engine speed. But for pure petrol the thermal efficiency is about $14.2 \%$ only. This is because of latent heat of vaporisation of ethanol and diethyl ether fuel blends which is greater than that of petrol. Since it will reduce the intake charge temperature thereby density of intake charge has increased, results the volumetric efficiency has increased. It will cause the increase in brake thermal efficiency for higher percentage of ethanol and diethyl ether blends. Moreover diethyl ether blends have more volatile than petrol so that complete combustion takes place thereby increase in thermal efficiency.

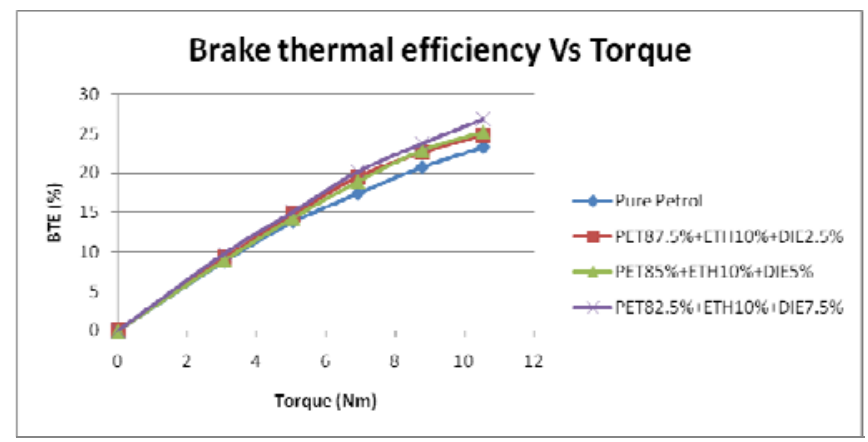

FIGURE III. VARIATION OF BRAKE THERMAL EFFICIENCY WITH ENGINE TORQUE

\section{B. Combustion Analysis}

1) Pressure-crank angle diagram: Figure IV shows the effect of adding ethanol and Diethyl ether to petrol fuel on the pressure- crank angle diagram. It can be seen from this Figure that the pure petrol has maximum pressure than blended fuel. The maximum pressure for pure petrol is 28 bar. However the same Figure shows that increasing the diethyl ether percentage (2.5\%, $5 \%$ and $7.5 \%)$ results in a decrease of the maximum pressure to a value of 27.5, 26 and 23 bar respectively. This may be explained as follows: the addition of ethanol and diethyl ether to petrol has two effects on the fuel properties; since the octane number of diethyl ether is much greater than that of petrol and the latent heat of evaporation of ethanol is much greater than that of petrol. Ethanol addition helps to delay the chain reactions of the end gas; the second is a decrease in heating value or calorific value.

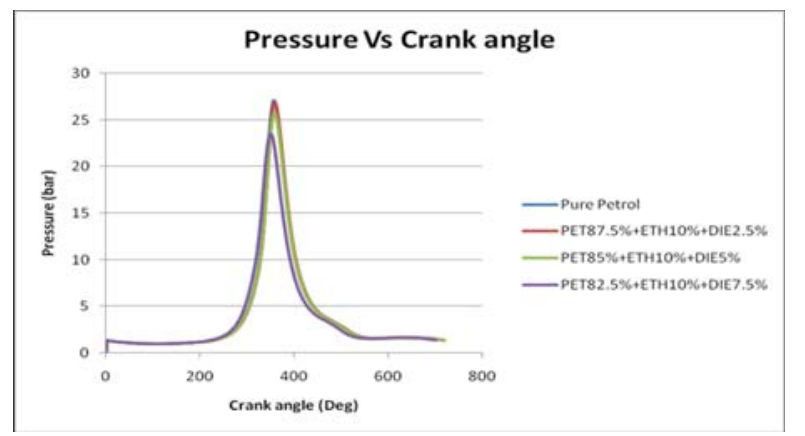

FIGURE IV. VARIATION OF PRESSURE-CRANK ANGLE AT FULL LOAD

2) Heat release Rate-crank angle diagram: Figure $\mathrm{V}$ shows the effect of adding ethanol and diethyl ether to petrol fuel on the heat release rate diagram. It can be seen from this figure the maximum heat release rate $40 \mathrm{~J} / \mathrm{deg}$ CA occurs for pure petrol 20 degrees after TDC. By adding ethanol and diethyl ether with petrol the flame speed may be increased to some extent thereby the maximum heat release rate occurs 18.5, 16.5 and 16 degrees after TDC for 2.5, 5 and 7.5\% of diethyl ether blends respectively. The addition of ethanol and diethyl ether with pure petrol decreases the overall heating value therefore the heat release rate as reduced 40J/Deg CA, 39.5J/Deg CA and 34J/Deg CA for 2.5\%, 5\% and $7.5 \%$ diethyl ether blends compared to the pure petrol. The negative heat release rate for the ethanol and diethyl ether blends has almost same compare to the pure petrol. This is due to the increase of latent heat of vaporization of the blends.

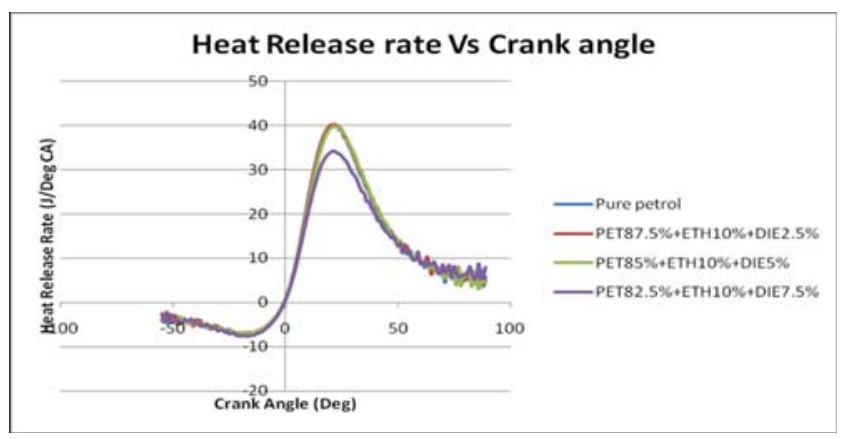

FIGURE V. VARIATION OF HEAT RELEASE RATE-CRANK ANGLE AT FULL LOAD

3) Cumulative heat release-crank angle: Figure VI shows the effect of ethanol and diethyl ether adding to petrol fuel on cumulative heat release diagram. The cumulative heat release mainly depends on the heat input and combustion efficiency. For this particular application the combustion efficiency is taken as constant but the heat input to the engine is varied by adding ethanol and diethyl ether with various percentages to the pure petrol. So, the overall calorific value of the mixture decreases with the percentage of increase of diethyl ether. So, the cumulative heat release for the ethanol and diethyl ether added fuels may reduce because of the calorific value of the mixture. 


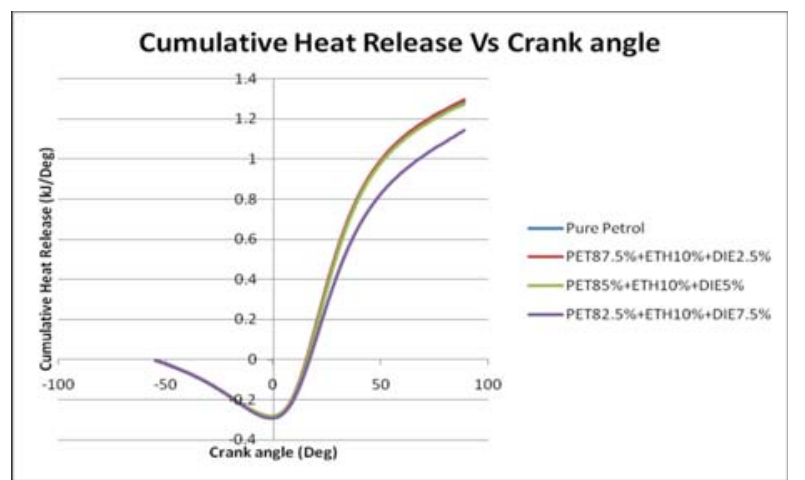

FIGURE VI. VARIATION OF CUMULATIVE HEAT RELEASE RATECRANK ANGLE AT FULL LOAD

\section{CONCLUSION}

1. Using di ethyl ether and ethanol as a fuel additive to unleaded gasoline causes an improvement in engine performance and exhaust emissions.

2. di ethyl ether addition results in an increase in brake power, brake thermal efficiency, volumetric efficiency, and fuel consumption by about $8.2 \%, 9 \%, 7 \%$ and $5.7 \%$ mean average values respectively. In addition, the brake specific fuel consumption decreases by about $2.4 \%$ mean average value.

3. Using di ethyl ether-unleaded gasoline blend leads to a significant reduction in exhaust emissions by about $26.5 \%$, $24.3 \%$ and $18.2 \%$ of the mean average values of CO, HC and NOx emission respectively for all engine torque. On the other hand carbon dioxide emission $\left(\mathrm{CO}_{2}\right)$ increases for all engine torque values.

4. By adding the di ethyl ether with gasoline the flame speed will increase, so that the spark timing of ethanol and di ethyl ether blends has to be optimized. This may improve the performance.

5. The peak pressure occurs in advance for di ethyl ether blends compared pure gasoline. So spark timing has to be retarded. This may influence the performance characteristics.

6. By adding the di ethyl ether with pure gasoline with various percentages, the octane number of di ethyl ether blends are increased due to highly volatile. This leads to use of higher compression ratio and hence higher power output. So, brake thermal efficiency of ethanol blends is also increased.

7. Among various blends, $7.5 \%$ of di ethyl ether and $10 \%$ ethanol addition to gasoline gave the best results in performance and emission.

\section{ACKNOWLEDGEMENT}

The author would like to thank the technical staff of the ICE laboratory at the Mechanical Engineering Department of Sona College of Technology.

\section{REFERENCES}

[1] Houghton-Alico D (1982), Alcohol fuels production and potential, Colorado.
[2] EL-Kassaby M M (1993), Effect of using differential ethanol-gasoline blends at different compression ratio on SI engine, Alexandria Engineering, pp.135-145.

[3] P. Pruksathorn and T. Vitidsant (2009), production of Pure Ethanol from Azeotropic Solution by Pressure Swing Adsorption, American Journal of Engineering and applied Sciences, 2: 1-7. DOI:10.3844/ajeassp.2009.1.7

[4] Syed Kaleemuddin and G.A.P. Rao (2009), Development of Dual Fuel Single Cylinder Natural Gas engine an Analysis and Experimental Investigation for performance and Emission, American journal of Applied sciences, 6:929-936. DOI: 10.3844/ajessp.2009.929.936.

[5] Balaji et al (2010), Emission and Combustion Characteristics of SI engine working under gasoline blended with Ethanol Oxygenated Organic Compounds, American journal of environmental Sciences 6(6): 495-499.

[6] Kapadi ss, Vijay VK, Rajesh SK and Prasad R. Upgrading biogas for utilization as a vehicle fuel. Asian Journal on Energy and Environment 2006; 7: 387-393.

[7] Uguluru A and Oztuna S. A comparative analysis study of alternative energy sources for automobiles. Int. J. Hydrogen energy 2015;40:1-11.

[8] Balki MK, Sayin C, and Canakci M. The effect of different alcohol fuels on the performance, emission and combustion characteristics of a gasoline engine. Fuel 2014;115:901-906. 